\title{
Syndromic Trends in the Sexually Transmitted Diseases (STD) among Patients Visiting STD Clinic of a Tertiary Hospital in the National Capital Region
}

\author{
Megha Khobragade', Niti Khunger ${ }^{2}$, Ashok Kumar Saxena ${ }^{3}$, Ameeka Shereen Lobo ${ }^{4}$, \\ Sumathi Murlidhar ${ }^{5}$, Aradhana Bhargava ${ }^{6}$
}

${ }^{1}$ Assistant Director General, Ministry of Health and Family Welfare, Govt. of India.

${ }^{2}$ Professor and HoD, ${ }^{3}$ Consultant, ${ }^{5}$ Professor and Consultant, ${ }^{6}$ Associate Professor and Specialist, Skin Department, Safdarjung Hospital, New Delhi, India.

${ }^{4} \mathrm{MSN}, \mathrm{MPH}$.

DOI: https://doi.org/10.24321/2454.325X.202010

\section{I $\quad \mathbf{N} \quad \mathbf{F} \quad \mathbf{O}$}

\section{Corresponding Author:}

Ameeka Shereen Lobo, MSN, MPH.

E-mail Id:

lobo.ameeka.shereen@gmail.com

Orcid Id:

https://orcid.org/0000-0002-5213-5105

How to cite this article:

Khobragade M, Khunger N, Saxena AK, Lobo AS, Murlidhar S, Bhargava A. Syndromic Trends in the Sexually Transmitted Diseases (STD) among Patients Visiting STD Clinic of a Tertiary Hospital in the National Capital Region. Int J Preven Curat Comm Med 2020; 6(2): 28-34.

Date of Submission: 2020-10-10

Date of Acceptance: 2020-11-02

\section{$\begin{array}{llllllll}\mathbf{A} & \mathbf{B} & \mathbf{S} & \mathbf{T} & \mathbf{R} & \mathbf{A} & \mathbf{C} & \mathbf{T}\end{array}$}

Sexually transmitted diseases or infections are a major threat to the public. Every year more than one million people acquire it globally. The objectives of this study were: a) to identify the number of patients tested for STDs, b) to assess the number of patients tested positive for STDs, c) to understand the trends of STD syndrome among the patients from January 2018 to June 2019. Data of patients visiting the STD Outpatient Department (OPD) of Safdarjung Hospital, New Delhi with symptoms related to STI/ STD was analysed. Data of patients who visited the OPD for consultation was available, and was used as proxy denominator to guide the analyses. Descriptive analyses were conducted using this dataset. The total number of patients in 2018 was 7363, out of which 4089 (55.53\%) were males. In 2019, the total number of patients between January and June was 4346 , with an almost similar proportion of males (2241-51.56\%). Of 7363 patients that visited the clinic, $19.7 \%$ of patients tested positive for one or the other STD in 2018, whereas from January to June $2019,18.38 \%$ patients tested positive for STD. A total of 1561 cases of Vaginal/ Cervical discharge was seen across the span of 18 months in 2018. This analysis gives an understanding of the number of patients with STD symptoms and syndromes over a period of 18 months at a tertiary level STD centre in Delhi. Since the data available is only for one centre, the results cannot be generalized to the wider population.

Keywords: Syndromes, Sexually Transmitted Diseases, Sexually Transmitted Infections, Trends 


\section{Background}

Sexually Transmitted Diseases (STDs) or Sexually Transmitted Infections (STIs) are a major threat to the public. Despite being recognised as having significantly high global incidence diseases such as gonorrhoea, chlamydia, syphilis and trichomoniasis, have not been researched enough. ${ }^{1,2}$ Every year more than one million people acquire STIs globally. ${ }^{1,3}$ During sexual contact, more than 30 different bacteria, viruses and parasites may be transmitted. ${ }^{3}$ Of these, eight pathogens may lead to STDs. Syphilis, gonorrhoea, chlamydia and trichomoniasis are curable STIs, while infections such as hepatitis B, Human Immunodeficiency Virus (HIV), Human Papilloma Virus (HPV) and Herpes Simplex Virus (HSV) are incurable. ${ }^{2,3}$

According to the Global Burden of Disease (GBD) data, the global DALYs towards HIV/AIDS and STIs have increased since 1990 with STIs being $17^{\text {th }}$ position in the year 2017, whereas in India no changes have been observed. ${ }^{4}$ In the U. S, there are 20 million new cases every year which mainly comprises of people aged between 15 to 24 years. ${ }^{5}$ According to a study conducted in the year 2002-2003 by Indian Council of Medical Research (ICMR), $6 \%$ of the adult population in India has one or more STI with the occurrence of around 30-35 million episodes of STI every year in India. ${ }^{6}$

STIs left untreated can lead to a range of adverse outcomes, including Pelvic Inflammatory Disease (PID), ectopic pregnancy, abortions, congenital infections and even deaths. ${ }^{7}$ It also leads to infertility and mother-to-child transmission of infection, resulting in still births, neonatal death, Low Birth Weight (LBW), sepsis, pneumonia, congenital deformities, prematurity and neonatal conjunctivitis. ${ }^{3}$ The 2018 STD surveillance report of Centre for Disease Control (CDC) states that there is a $22 \%$ increase in neonatal deaths due to syphilis from 2017 to 2018; an increase of $19 \%$ in chlamydia cases, $63 \%$ increase in gonorrhoea cases, $71 \%$ increase in primary and secondary syphilis and $185 \%$ increase in Congenital Syphilis (CS) since $2014 .{ }^{8}$ According to WHO, in the year 2016, there were one million pregnant women with active syphilis, 3,50,000 adverse birth outcomes and 2,00,000 still births ${ }^{3,7}$ A global estimate of 2,00,000 foetal and neonatal deaths every year due to syphilis in pregnancy and about 2,80,000 cervical cancer deaths due to Human Papillomavirus (HPV) have been reported by the WHO. ${ }^{9}$

This group of diseases has a major effect not because of their impact on the sexual and reproductive issues, but due to the absence of symptoms or the presence of mild symptoms, which are often overlooked. ${ }^{7}$ The usual signs and symptoms include unusual discharge from penis or vagina, genital sores or warts, painful or frequent urination, itching or redness in the genital area, abnormal vaginal odour, blisters or sores in and around the mouth, abdominal pain, fever, anal itching, soreness or bleeding. ${ }^{10}$ Individuals can also present with syndromes such as cervicitis, urethritis, PID, prostatitis, genital ulcers, enteric infections, epididymitis, hepatitis, ophthalmia neonatorum, vulvovaginitis and vaginosis. ${ }^{11}$ Apart from these, it also leads to other severe concerns - infections such as herpes and syphilis increase the possibility of acquiring HIV infection by three folds. STIs such as gonorrhoea and chlamydia are the major causes of PID and infertility in women. ${ }^{3}$ Steps have been taken to prevent and control STIs by World Health Organization (WHO) and various other partners by launching a program for Elimination of Mother-To-Child Transmission (EMTCT) of syphilis and HIV globally in the year 2007.?

India continues to have a sizeable proportion of people suffering from STDs. The objective of this paper is to describe the trends in the occurrence of symptoms/syndromes with respect to various STDs among the patients of a STD clinic of a tertiary hospital in the national capital between January 2018 and June 2019.

\section{Objectives}

The objectives of this study were:

- To identify the number of patients tested for STDs from January 2018 to June 2019

- To assess the number of patients tested positive for STDs from January 2018 to June 2019

- To understand the trends of STD syndrome among the patients from January 2018 to June 2019

\section{Methodology}

For this study, data of patients visiting the STD Outpatient Department (OPD) of Safdarjung Hospital, New Delhi with symptoms related to STI/STD was analysed. These patients are referred to the Apex Regional STD Centre for diagnosis and further management, including investigations. Among these, patients who are suspected of having a STI based on history and examination are asked to undergo investigations for confirmation of diagnosis. Depending on the laboratory test results, further line of treatment for the individual patient is decided.

The centre is well monitored and managed by co-ordinated efforts of a team of experts from the Dermatology, Microbiology, Obstetrics and Gynaecology (OBGY), and Community Medicine departments as well as the Apex Regional STD Reference laboratory of the tertiary-level hospital. Quality of the investigations undertaken as well as documentation of all processes and results are maintained at all times, as per the requirement of ISO 15189:2012 for which the laboratory is accredited by the National Accreditation Board for Testing and Calibration Laboratories, India.

The data maintained in the laboratory consist of eight sections. They are syndromic validation of patients/ samples received by centre, number of gonococci cultures and anti-microbial resistance studies performed, number of 
other STI/RTI pathogens cultured, status of consumables like test kits, AMC status of equipments, details of trainings conducted, details of ILC/ EQAS conducted and details of $\mathrm{STI} / \mathrm{RTI}$ research work by the centre.

The STDs tested in the laboratory are divided into the following syndromes: Genital Ulcer Disease - Non-Herpetic (GUD-NH), Genital Ulcer Disease - Herpetic (GUD-H), Urethral Discharge Syndrome, Oral/ Anorectal Discharge Syndrome, Vaginal Discharge Syndrome, Cervical Discharge Syndrome, Hepatitis B and Hepatitis C. However, in this study, data available for analyses included the following the laboratory carries out tests and validates the following syndromes GUD-NH, GUD-H, Urethral Discharge (UD), Vaginal/Cervical Discharge (VCD), Genital Warts (GW), Hepatitis B and Hepatitis C.

The laboratory tests performed for each syndrome is given in table 1.

The data available for analyses include cases of one or more of these above-mentioned syndromes from January 2018 to June 2019. Additionally, data of patients who visited the OPD for consultation was also available and was used as proxy denominator to guide the analyses. Descriptive analyses were conducted using this dataset.

\section{Result}

The Apex Regional STD centre saw a substantial number of patients, both males and females, over a period of 18 months from January 2018 to June 2019. The total number of patients in 2018 was 7363, out of which 4089 (55.53\%) were males. In 2019, the total number of patients between January and June was 4346, with an almost similar proportion of males (2241 - 51.56\%).

In Table 2, we can also see that a higher proportion of male patients visited the STD clinic during every month of 2018, except in February 2018 when more female patients visited the clinic. In December 2018, the proportion of male patients visiting the clinic was almost twice that of female patients (68.71\% vs $31.21 \%)$. An almost similar trend in the proportion of male and female patients visiting the clinic was seen between January and June 2019, with more males visiting the clinic every month, except in March and April 2019.

Table I.List of laboratory tests performed for different syndromes at the Apex Regional STD centre from January 2018 to June 2019

\begin{tabular}{|c|c|c|}
\hline $\begin{array}{l}\text { GUD - Non Herpetic } \\
\text { syndrome }\end{array}$ & Syphilis & Dark Field Microscopy \\
\hline & & Veneral Disease Research Laboratory (VDRL) Test -Qualitative \\
\hline & & $\begin{array}{l}\text { VDRL Test - Quantitative ( No of samples showing titres } \geq 1: 8+v e) \\
\qquad /<1: 8\end{array}$ \\
\hline & & Rapid Plasma Reagin (RPR) Test- Qualitative (ICTC) \\
\hline & & RPR Test - Quantitative ( No of samples showing titres $\geq 1: 8+v e$ ) \\
\hline & & Trepenoma Pallidum Haemagglutination test (TPHA) \\
\hline & & Fluorescent Trepenomal antibody absorption test (FTA-Abs) \\
\hline & & $\begin{array}{l}\text { Trepenoma Pallidum Enzyme Linked Immunosorbent Assay (TP } \\
\text { ELISA) IgM/IgG }\end{array}$ \\
\hline & Chancroid & Gram stain of ulcer smear \\
\hline & & Culture \\
\hline & Donovanosis & Crushed Tissue smear for Donovan bodies \\
\hline \multirow[t]{3}{*}{$\begin{array}{l}\text { GUD Herpetic } \\
\text { syndrome }\end{array}$} & HSV II & Ulcer smear for Multinucleated Giant Cell (MNGC) \\
\hline & & Anti-Herpes Simplex Virus (HSV II) gG2 type specific IgG \\
\hline & & ELISA Antigen \\
\hline \multirow[t]{5}{*}{$\begin{array}{l}\text { Urethral Discharge } \\
\text { syndrome }\end{array}$} & Neisseria gonorrhoea & GC Smear - Male (Discharge) \\
\hline & & GC Culture -Male \\
\hline & Chlamydia trachomatis & ELISA Antigen \\
\hline & & DFA \\
\hline & Trichomonas vaginalis & Direct wet mount- Discharge \\
\hline
\end{tabular}




\begin{tabular}{|c|c|c|}
\hline & & Urine sediment \\
\hline $\begin{array}{c}\text { Oral / Anorectal } \\
\text { Discharge syndrome }\end{array}$ & Neiserria gonorrhoea & Culture \\
\hline & & GC Smear - Discharge \\
\hline & Chlamydia trachomatis & GC Culture \\
\hline & & ELISA Antigen \\
\hline $\begin{array}{c}\text { Vaginal discharge } \\
\text { syndrome }\end{array}$ & Trichomonas vaginalis & DFA \\
\hline & & Direct wet mount - Vaginal discharge \\
\hline & Candida species & Culture \\
\hline & & KOH \\
\hline & & Culture \\
\hline & Bacterial vaginosis & Gram stain \\
\hline Cervical discharge & Neiserria gonorrhoea & GC Smear - Female \\
\hline syndrome & & GC Culture - Female \\
\hline & & ELISA Antigen \\
\hline & & DFA \\
\hline Chlamydia trachomatis & & Direct wet mount-discharge \\
\hline Hepatitis B & & HbsAg \\
\hline Others & & Anti HCV \\
\hline & & Semen Analysis done \\
\hline & & VDRL test for other than GUD-NH \\
\hline & & Prichomonas vaginalis \\
\hline
\end{tabular}

Table 2.Number of patients tested for STDs at the Apex Regional STD centre from January 2018 to June 2019

\begin{tabular}{|c|c|c|c|c|c|c|}
\hline \multirow{2}{*}{} & \multicolumn{3}{|c|}{$\mathbf{2 0 1 8}$} & \multicolumn{3}{c|}{$\mathbf{2 0 1 9}$} \\
\cline { 2 - 7 } & Male & Female & Total (100\%) & Male & Female & Total (100\%) \\
\hline January & $349(52.40 \%)$ & $317(52.40 \%)$ & 666 & $419(53.86 \%)$ & $359(46.14 \%)$ & 778 \\
\hline February & $250(47.71 \%)$ & $274(52.29 \%)$ & 524 & $381(53.81 \%)$ & $327(46.19 \%)$ & 708 \\
\hline March & $321(55.83 \%)$ & $254(44.17 \%)$ & 575 & $356(47.21 \%)$ & $398(52.79 \%)$ & 754 \\
\hline April & $294(57.09 \%)$ & $221(42.91 \%)$ & 515 & $337(46.81 \%)$ & $383(53.19 \%)$ & 720 \\
\hline May & $344(57.53 \%)$ & $254(42.47 \%)$ & 598 & $414(54.40 \%)$ & $347(45.60 \%)$ & 761 \\
\hline June & $306(55.64 \%)$ & $244(44.36 \%)$ & 550 & $334(53.44 \%)$ & $281(44.96 \%)$ & 625 \\
\hline July & $371(56.30 \%)$ & $288(43.70 \%)$ & 659 & - & - & - \\
\hline August & $357(54.26 \%)$ & $301(45.74 \%)$ & 658 & - & - & - \\
\hline September & $309(46.96 \%)$ & $301(45.74 \%)$ & 658 & - & - & - \\
\hline October & $351(55.98 \%)$ & $276(44.02 \%)$ & 627 & - & - & - \\
\hline November & $372(56.62 \%)$ & $285(43.48 \%)$ & 657 & - & - & - \\
\hline December & $465(68.79 \%)$ & $211(31.21 \%)$ & 676 & - & - & - \\
\hline Total & $4089(55.53 \%)$ & $3226(43.81 \%)$ & 7363 & $2241(51.56 \%)$ & $2095(48.20)$ & 4346 \\
\hline
\end{tabular}


Table 3.Patients who tested positive for STDs at the Apex Regional STD centre from January 2018 to June 2019

\begin{tabular}{|c|c|c|c|c|}
\hline & \multicolumn{2}{|c|}{$\mathbf{2 0 1 8}$} & \multicolumn{2}{c|}{2019} \\
\hline & $\begin{array}{c}\text { Total No. of } \\
\text { patients }\end{array}$ & $\begin{array}{c}\text { No. (\%) of patient tested } \\
\text { positive }\end{array}$ & $\begin{array}{c}\text { Total No. of } \\
\text { patients }\end{array}$ & $\begin{array}{c}\text { No. (\%) of patient tested } \\
\text { positive }\end{array}$ \\
\hline January & 666 & $196(29.42 \%)$ & 778 & $165(21.20 \%)$ \\
\hline February & 524 & $128(24.42 \%)$ & 708 & $148(20.90 \%)$ \\
\hline March & 575 & $114(19.82 \%)$ & 754 & $151(20.02 \%)$ \\
\hline April & 515 & $78(15.14 \%)$ & 720 & $123(17.08 \%)$ \\
\hline May & 598 & $145(24.24 \%)$ & 761 & $126(16.55 \%)$ \\
\hline June & 550 & $104(18.90 \%)$ & 625 & $86(13.76 \%)$ \\
\hline July & 659 & $81(12.29 \%)$ & - & - \\
\hline August & 658 & $112(17.02 \%)$ & - & - \\
\hline September & 658 & $124(18.84 \%)$ & - & - \\
\hline October & 627 & $115(18.34 \%)$ & - & - \\
\hline November & 657 & $123(18.72 \%)$ & - & - \\
\hline December & 676 & $131(19.37 \%)$ & - & $799(18.38 \%)$ \\
\hline Total & 7363 & $1451(19.70 \%)$ & 4346 & \\
\hline
\end{tabular}

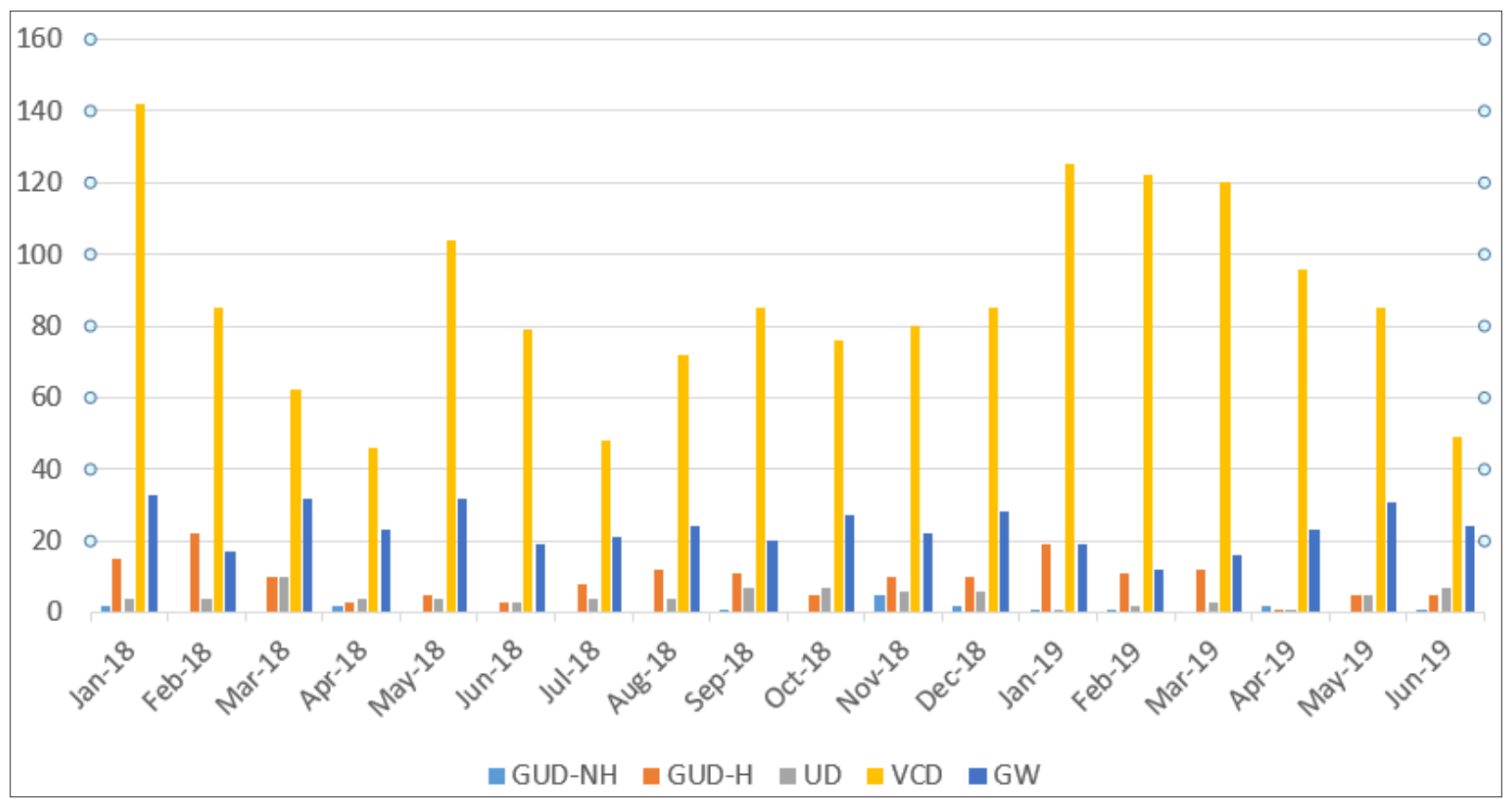

Figure I.Graphical representation on the trend of presence of syndromes among STD patients from January 2018 to June 2019

The STD data available for analyses included the following diseases - Gonorrhoea, Syphillis, Herpes Simplex Virus 1 and 2, Chlamydiasis, Chanchroid, Donovanosis, Lympho Granuloma Venerum, Trichomoniasis, Bacterial Vaginosis, Vulvo-Vaginal Candidiasis, Hepatitis B and C and HIV. Syndromic trends among STD patients from January 2018 to June 2019 are also observed. Table 3, describes the number of patients tested positive between January 2018 and June 2019. In the year 2018, out of 7363 patients that visited the clinic, $19.7 \%$ of patients tested positive for one or the other STD, whereas from January to June 2019, $18.38 \%$ patients tested positive for STD. The proportion of patients testing positive for STDs in the year 2018 was highest in the month of January (29.42\%), significantly higher than the proportion observed in July 2018, which was the least that year $(12.29 \%$ ) ( $p$ value $<0.001$ ). Similarly, 
in 2019, January witnessed a significantly higher proportion of confirmed STD cases among the patients who visited the clinic (21.2\%) as compared to June 2019 (13.76\%) (p value $=0.0029)$.

In Figure 1, it is seen that the number of patients with presence of VCD was significantly high in comparison to the other syndromes. The total number of VCD cases were 1561 across the span of 18 months, with the highest number of diagnosed cases (142) in the month of January 2018, while the least number of diagnosed cases were seen in April 2018 (46 cases). In 2019, the number of cases showed a slow receding trend with the number of cases in the first three months being 125, 122 and 120 respectively and in June 2019 only 49 cases were registered.

The presence of GUD-NH was the least among all the syndromes with 17 cases over a period of 18 months, being significantly less than 1516 cases of VCD ( $\chi 2=1163$, $P<0.04)$ which was observed in majority of the patients.

\section{Discussion}

In the year 2018, total number of patients in the Apex Regional STD centre was 7363, while 4346 patients visited the centre over 6 months between January and June 2019. This was a little above the $50 \%$ mark of 2018 , indicative of a consistent trend in the number of patients visiting the centre. Results showed that more males generally visited the STD centre for diagnosis and treatment. In December 2018 , the proportion of male patients visiting the clinic was almost twice that of female patients (68.71\% vs $31.21 \%$ ). The trend of patients testing positive for any one STD was observed to be significantly high around January, followed by a decline and then increase again towards the end of the year. The number of patients with presence of VCD syndrome was significantly higher than the other syndromes in the span of 18 months (total 1516 cases), while GUD-NH was the least prevalent among all the syndromes (only 17 cases) over a period of 18 months.

A similar trend was seen in a study conducted in a tertiary centre in Lucknow to estimate the prevalence of Reproductive Tract Infections (RTIs) and its associated factors in women of reproductive age group (18 to 45 years). The study found that the prevalence of RTIs among 318 women was $9.7 \%$. Of various infections, $11.5 \%$ patients had candidiasis, $4.1 \%$ had chlamydia and syphilis each, $1.73 \%$ had bacterial vaginosis and $0.57 \%$ had trichomoniasis. No patients were found gonorrhoea positive. However, $52.8 \%$ reportedly presented with genital discharge and $45.2 \%$ had abdominal pain. ${ }^{12}$ In this study too, most patients reported with complaints of discharge.

Another study was conducted to determine the prevalence of Chlamydia trachomatis and Neisseria gonorrhoeae coinfections among patients who were diagnosed newly for syphilis. Swabs were extracted from urethra, rectum, pharynx and cervix. Totally, 548 patients were screened of which 488 were men and 60 were women. Around 15.9\% patients were detected to have co-infections. Majority $(86.2 \%)$ of the co-infections were asymptomatic. The prevalence of gonococcal infection was $8.8 \%$, while it was $11.1 \%$ for chlamydial infection. ${ }^{13}$

A study on patterns and prevalence of different STIs, its trend epidemiological factors and behaviour was conducted among patients attending STI clinic in a tertiary medical college and hospital in North India from April 2007 to March 2014. A total of 5468 patients visited the STI clinic of which 3908 were diagnosed with STIs. Majority of the patients were married male patients in their 30s. Around $21.75 \%$ (850) had herpes genitalis, $10.61 \%$ (415) had genital warts, $6.11 \%$ (239) had molluscum contagiosum, $2.71 \%$ (106) had urethral discharge and $2.07 \%$ (81) had syphilis. HIV was found in $10.59 \%$ (414) patients and $38.48 \%$ had viral infections. ${ }^{14}$ This study supports the pattern of genital warts and urethra discharge, like in the current analyses. However, further analysis is required to understand the relation between the symptoms and the syndromes.

Patterns of STIs were determined in a tertiary care hospital in Eastern India. Consecutive patients attending the STI clinic were included in the study from January 2011 to December 2011. Among the STIs, genital herpes was the most common. Viral STIs like condyloma acuminate, gential herpes and molluscum contagiousum were more prevalent than the non-viral STIs like GUD-NH and syphilis. ${ }^{15}$

A 2006 study on changing trends in sexually transmitted infections at a regional STD centre in North India was conducted by comparing the data across many years from 1990 to 2004 . Out of 78,617 patients, 12,709 of them had STIs. Genital discharges were prevalent between 1990 and 1993, while GUD was predominant in the later years. A significant rise in the cases of syphilis, herpes progenitalis and genital warts were seen over time. A reduction in cases of chancroid, Lymphogranulomavenereum (LGV), donovanosis, candidiasis, trichomoniasis and bacterial vaginosis were also noticed. ${ }^{16}$ In the present analysis, patients with VCD have been reported in majority. Whereas, patients presenting with GUD were the least.

Sexually transmitted diseases tend to be underreported, due to the nature of their epidemiology. As a result, the symptoms in STD may go unnoticed, thus increasing its severity due to its adverse outcomes. The increase in numbers shows that people are unaware of the preventive measures that needs to be taken care of that could avert the occurrence of the disease. Further, more males have visited the centre, indicating that females are either less comfortable with presenting to a clinic with STD related symptoms, or they are unaware that this is a problem and 
needs investigation and treatment. Routine check-ups can help in ruling out the STDs because of the presence or absence of mild symptoms in patients. Hence, awareness about STDs, diagnostic measures and preventive measures can enable to decrease the stigma associated with it and also help reduce the number of cases in the long run.

This analysis gives an understanding of the number of patients with STD symptoms and syndromes over a period of 18 months at a tertiary level STD centre in Delhi. However, since the data available is only for one centre, the results cannot be generalized to the wider population. Also, data for each specific disease within the individual syndromes was not available. These are some limitations of this data.

\section{Conflict of Interest: None}

\section{References}

1. Unemo M, Bradshaw CS, Hocking JS, de Vries HJC, Francis SC, Mabey D et al. Sexually transmitted infections: challenges ahead. Lancet Infect Dis 2017; 17(8): e235-e279.

2. Gerbase AC, Rowley JT, Mertens TE. Global epidemiology of sexually transmitted diseases. The Lancet 1998; 351: S2-4.

3. Sexually transmitted infections (STIs) [Internet]. [cited 2019 Oct 14]. Available from: https://www.who.int/ news-room/fact-sheets/detail/sexually-transmittedinfections-(stis).

4. GBD Compare / IHME Viz Hub [Internet]. [cited 2019 Oct 14]. Available from: http://vizhub.healthdata.org/ gbd-compare.

5. STDs/STIs [Internet]. American Sexual Health Association. [cited 2019 Oct 14]. Available from: http:// www.ashasexualhealth.org/stdsstis/.

6. Sexually transmitted infections (STIs) | National Health Portal Of India [Internet]. [cited 2019 Oct 14]. Available from: https://www.nhp.gov.in/disease/reproductivesystem/sexually-transmitted-infections-stis.

7. Korenromp EL, Rowley J, Alonso M, Mello MB, Wijesooriya NS, Mahiané SG et al. Global burden of maternal and congenital syphilis and associated adverse birth outcomes-Estimates for 2016 and progress since 2012. PLOS ONE 2019; 14(2): e0211720.

8. CDC. 2018 Sexually Transmitted Disease Surveillance [Internet]. Centres for Disease Control and Prevention. 2019 [cited 2019 Oct 14]. Available from: https://www. cdc.gov/std/stats18/default.htm.

9. World Health Organization. Report on global sexually transmitted infection surveillance 2018 [Internet]. WHO. [cited 2019 Oct 14]. Available from: http:// www.who.int/reproductivehealth/publications/stissurveillance-2018/en/.

10. What are the symptoms of sexually transmitted diseases (STDs) or sexually transmitted infections (STIs)?
[Internet]. http://www.nichd.nih.gov/. [cited 2019 Oct 14]. Available from: http://www.nichd.nih.gov/health/ topics/stds/conditioninfo/symptoms.

11. Chernesky MA, Patrick D. Syndromes associated with sexually transmitted infections. Can J Infect Dis Med Microbiol 2005; 16(1): 13-14.

12. Chaudhary N, Kalyan R, Singh M, Agarwal J, Qureshi S. Prevalence of reproductive tract infections in women attending a tertiary care center in Northern India with special focus on associated risk factors. [cited 2020 Jan 29]. Available from: https://www.ncbi.nlm.nih.gov/ pubmed/31922100.

13. Rob F, Jůzlová K, Kružicová Z, Vaňousová D, Lásiková Š, Sýkorová B et al. Prevalence of Chlamydia trachomatis and Neisseria gonorrhoeae co-infections among patients with newly diagnosed syphilis: a single-centre, crosssectional study. [cited 2020 Jan 29]. Available from: https://www.ncbi.nlm.nih.gov/pubmed/31951687

14. Banger HS, Sethi A, Malhotra S, Malhotra SK, Kaur T. Clinico-epidemiological profile of patients attending Suraksha Clinic of tertiary care hospital of North India. [cited 2020 Jan 29]. Available from: https://www.ncbi. nlm.nih.gov/pmc/articles/PMC5389216/.

15. Sarkar S, Shrimal A, Das J, Choudhury S. Pattern of Sexually Transmitted Infections: A Profile from a Sexually Transmitted Infections Clinic of a Tertiary Care Hospital of Eastern India. [cited 2020 Jan 30]. Available from: https://www.ncbi.nlm.nih.gov/pmc/ articles/PMC3728864/.

16. Ray K, Bala M, Gupta SM, Khunger N, Puri P, Muralidhar $\mathrm{S}$, Kumar J. Changing trends in sexually transmitted infections at a Regional STD Centre in north India. [cited 2020 Jan 30]. Available from: https://www.ncbi.nlm. nih.gov/pubmed/17213525. 